\title{
Males are attracted by their own courtship signals
}

\author{
Pablo D. Ribeiro • John H. Christy • \\ Rebecca J. Rissanen • Tae Won Kim
}

Published online: 10 January 2007

(C) Springer-Verlag 2007

\section{Erratum to: Behav Ecol Sociobiol (2006) 61:81-89}

Due to a technical error, a wrong version of Fig. 4a has been published. Please find herein the correct version of Fig. 4a.

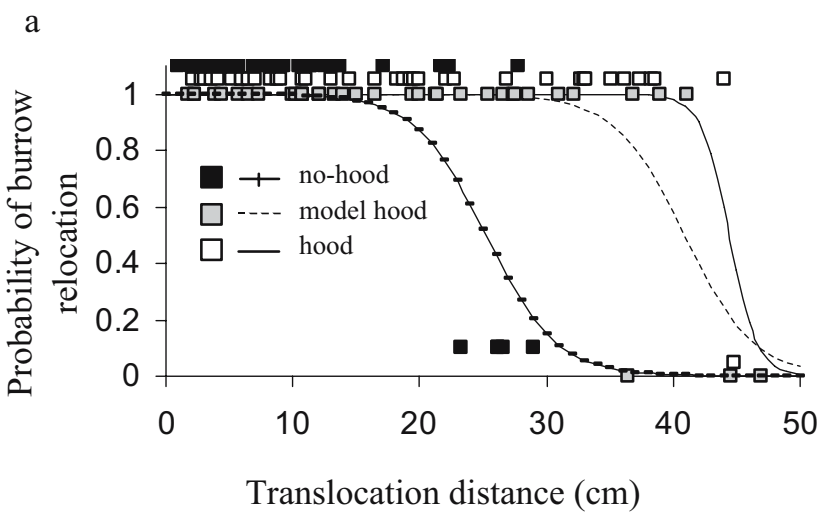

b

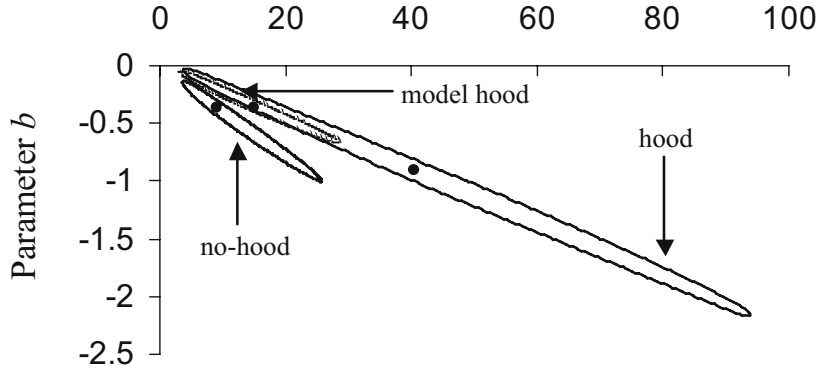

Parameter $a$

Fig. 4 a Probability of relocating a burrow in relation to the distance a male crab was moved. Boxes show success (1) or failure $(0)$, but for an easier graphical interpretation, different treatments were slightly separated along the vertical. Lines show the fitted logistic regression. b Ellipsoids of $95 \%$ joint confidence limits for both $a$ and $b$ parameters for the logistic regressions. Circles inside joint confidence limits correspond to the maximum likelihood estimates for each model. Hood males with hood around their burrow openings, model hood males without hoods but with model hoods added around their burrow openings, no-hood males without hoods 